\title{
Stilbene Derivatives as Human 5-HT 6 Receptor Antagonists from the Root of Caragana sinica
}

\author{
Dong Hyuk KIm, ${ }^{a, b}$ Soon-Hee KIM, ${ }^{a}$ Hyoung Ja KIm, ${ }^{a}$ Changbae JIN ${ }^{a}$ Kwang Chul Chung,,${ }^{b}$ and \\ Hyewhon RHIM*,a \\ ${ }^{a}$ Life Sciences Division, Korea Institute of Science and Technology; Seoul 136-791, Korea: and ${ }^{b}$ Department of Biology, \\ Yonsei University; Seoul 120-749, Korea. Received June 3, 2010; accepted September 6, 2010
}

The 5- $\mathrm{HT}_{6}$ receptor $\left(5-\mathrm{HT}_{6} \mathrm{R}\right)$ is a member of the class of recently discovered 5-hydroxytryptamine (5-HT) receptors. Due to the lack of selective $5-\mathrm{HT}_{6} \mathrm{R}$ ligands, the cellular signaling mechanisms of the 5-HT $\mathrm{R}$ are poorly understood. We previously developed a cell-based high-throughput screening (HTS) method for the 5$H_{T_{6}} R$ and screened synthetic chemical compounds. In the present study, we expanded our screening into natural products to find novel 5-HT 6 R ligands. We found that the ethyl acetate fraction from the root of Caragana sinica (537-18BE) produced the most potent antagonistic activity. After further isolation of 537-18BE, we found that three stilbene derivatives, (+)- $\alpha$-viniferin, miyabenol $C$ and pallidol, are active constituents of 537-18BE inhibiting the 5-HT ${ }_{6} \mathrm{R}$. Among them, $(+)-\alpha$-viniferin showed the most potent inhibition, and miyabenol $\mathrm{C}$ also produced a considerable inhibition. When examined effects on other neurotransmitters for selectivity, 537-18BE and three stilbene derivatives did not produce any notable effects on $5-\mathrm{HT}_{4}, 5-\mathrm{HT}_{7}$, or muscarinic acetylcholine $\mathrm{M1}$ $\left(M_{1}\right)$ receptors. Furthermore, 5-HT ${ }_{6} R$ antagonistic effects of $(+)$ - $\alpha$-viniferin, miyabenol $C$ and pallidol were confirmed on extracellular signal-regulated kinase 1 and 2 (ERK1/2) which exerts effects in downstream pathways of $5-\mathrm{HT}_{6} \mathrm{R}$ activation.

Key words serotonin; intracellular $\mathrm{Ca}^{2+}$; extracellular signal-regulated kinase 1/2; FDSS6000; Caragana sinica; stilbene derivative

Serotonin (5-hydroxytryptamine, 5-HT) is an important neurotransmitter found in both the central and peripheral nervous systems. ${ }^{1-3)} 5$-HT mediates its diverse physiological responses via at least 16 different 5-HT receptors that are grouped into seven distinct subfamilies, the $5-\mathrm{HT}_{1-7}$ receptors. The human 5-HT receptor subtype $6\left(5-\mathrm{HT}_{6} \mathrm{R}\right)$ is one of the most recently cloned receptors among the known 5-HT receptors and belongs to the family of G-protein-coupled receptors (GPCRs) that positively couple to adenylate cyclase. ${ }^{4-6)}$ The $5-\mathrm{HT}_{6} \mathrm{R}$ is mainly found in the central nervous system (CNS), and its abundant distribution in the limbic region, which participates in the control of mood and emotion, has generated much interest. ${ }^{7,8)}$ Despite intensive research attempts to identify selective $5-\mathrm{HT}_{6}$ ligands, only a very limited number of antagonists has progressed to clinical development. Furthermore, the cellular mechanisms underlying 5$\mathrm{HT}_{6} \mathrm{R}$-mediated behavioral changes are not well understood in the CNS. We previously developed a reliable cell-based high-throughput screening (HTS) method and screened synthetic chemical compounds to identify ligands of the 5$\left.\mathrm{HT}_{6} \mathrm{R}^{9}{ }^{9}\right)$ This HTS method measures 5-HT-induced $\mathrm{Ca}^{2+}$ increases using a promiscuous $\mathrm{G} \alpha_{15}$ protein that facilitates coupling of $\mathrm{G} \alpha_{\mathrm{S}}$-coupled receptors to phospholipase $\mathrm{C}$ and consequent intracellular $\mathrm{Ca}^{2+}$ release, which is subsequently detected using an FDSS6000 96-well fluorescence plate reader. We furthermore utilized the FDSS6000 system to examine the functions of the $5-\mathrm{HT}_{6} \mathrm{R}$ and its interacting proteins in several mammalian cell lines. ${ }^{10,11)}$

In the present study, as part of our continued efforts to identify novel 5- $\mathrm{HT}_{6}$ ligands, we used the FDSS6000 system to screen natural products. Among a library of natural products examined, we found that the ethyl acetate fraction from the root of Caragana sinica (537-18BE) showed the strongest inhibition on the $5-\mathrm{HT}_{6} \mathrm{R}$. The genus Caragana is a member of the family Fabaceae and is widely distributed throughout the Euro-Asian continent. More than 10 species in this genus have a long history of use in traditional medicines, and the medicinal use of Caragana species was first noted when $C$. sinica has been traditionally used in the treatment of asthenia syndrome, vascular hypertension, leukorrhagia, bruises and contused wounds. Recent in vivo and/or in vitro studies have provided some support for other traditional uses, e.g. anti-cancer, anti-inflammatory, phytoestrogenic, immunostimulant and immunosuppressant activities. ${ }^{12)}$ However, further studies to identify the active components and verify the pharmacological activities are needed. Therefore, we further isolated $537-18 \mathrm{BE}$ to find active components for $5-\mathrm{HT}_{6} \mathrm{R}$-mediated $\mathrm{Ca}^{2+}$ responses activity and found that three stilbene derivatives, $(+)-\alpha$-viniferin, miyabenol $\mathrm{C}$ and pallidol, produced an antagonistic effect to the $5-\mathrm{HT}_{6} \mathrm{R}$ in the human $5-\mathrm{HT}_{6} \mathrm{R}$ stably expressed HeLa and HEK293 cells.

\section{MATERIALS AND METHODS}

Plant Materials The root of $C$. sinica was collected at Changnyeong-gun, Gyeongsangnam-do, Korea in July 1995 and the plant was identified by Dr. J. H. Kwak at Sungkyunkwan University. The voucher specimen (537-18B) has been deposited in the laboratory of Korea Institute of Science and Technology (KIST).

Extract from $\boldsymbol{C}$. sinica and Fractionation The dried roots of $C$. sinica $(1.25 \mathrm{~kg})$ were cut into small pieces and extracted three times with methanol at room temperature. The methanol extract $(94.0 \mathrm{~g}, 7.5 \%)$ was suspended in water and then partitioned in turns with $\mathrm{CH}_{2} \mathrm{Cl}_{2}$, EtOAc and $n$-butanol. The EtOAc extract (537-18BE, $15.0 \mathrm{~g}$ ) was subjected to column chromatography using Sephadex LH-20 eluting with methanol to yield seven fractions (Fr. 1-Fr. 7). Fraction 5 $(2.6 \mathrm{~g})$ was divided by column chromatography over silica 
gel using $\mathrm{CH}_{2} \mathrm{Cl}_{2}$ : EtOAc: $\mathrm{MeOH}(4: 1: 0.7)$ system as eluent to give six fractions (Fr. 5a-Fr. 5f). Fraction $5 \mathrm{~b}$ (988 mg) was purified by column chromatography on LiChroprep RP-18 eluting with aqueous methanol $(53 \rightarrow$ $63 \%$ ) gradient system to yield ( + )- $\alpha$-viniferin $(680.4 \mathrm{mg}$, $0.054 \%$ ). Fraction $5 \mathrm{c}(465 \mathrm{mg})$ was purified by column chromatography on LiChroprep RP-18 eluting with $45 \%$ methanol system to yield miyabenol C (102 mg, 0.008\%). Fraction $4(510 \mathrm{mg})$ was subjected to column chromatography over silica gel using $\mathrm{CH}_{2} \mathrm{Cl}_{2}$ : EtOAc : $\mathrm{MeOH}(4: 1: 0.7)$ system to give four fractions (Fr. $4 \mathrm{a}-\mathrm{Fr}$. 4d). Fraction $4 \mathrm{a}$ $(30.5 \mathrm{mg})$ was purified by column chromatography using Toyopearl HW-40C eluting with $70 \%$ methanol to yield pallidol $(22.6 \mathrm{mg}, 0.002 \%)$. The structures of the three compounds were identified by direct comparison of the one and two-dimensional ${ }^{1} \mathrm{H}$ - and ${ }^{13} \mathrm{C}-\mathrm{NMR}$, mass and other physical and spectroscopic data with previously reported data. ${ }^{13-15)}$

Cell Culture and Transfection HeLa and HEK293 cells were grown in Dulbecco's modified Eagle's medium (DMEM) supplemented with 10\% fetal bovine serum, penicillin (100 units $/ \mathrm{ml})$, and streptomycin $(100 \mu \mathrm{g} / \mathrm{ml})$ at $37^{\circ} \mathrm{C}$ in a humidified atmosphere of $5 \% \mathrm{CO}_{2}$ and $95 \%$ air. HEK293 and HeLa cell lines stably expressing the human $5-\mathrm{HT}_{6} \mathrm{R}$, were selected with $800 \mu \mathrm{g} / \mathrm{ml}$ of $\mathrm{G}-418$ and hygromycin, respectively, and maintained with $400 \mu \mathrm{g} / \mathrm{ml}$ of each selection drug. For transient transfection of $\mathrm{G} \alpha_{15}$, $1 \times 10^{6}$ cells were placed on $100-\mathrm{mm}$ dishes and transfected with $\mathrm{G} \alpha_{15}$ using Lipofectamine 2000 (Invitrogen, CA, U.S.A.). After $6 \mathrm{~h}$, the cells were transferred to 96 -well black wall/clear bottom or 6-well plates and used within $18-24 \mathrm{~h}$.

Assay of 5-HT ${ }_{6}$ R Activity Using the FDSS6000 System Briefly, HeLa or HEK293 cells were loaded with the $\mathrm{Ca}^{2+}$ indicator dye Fluo-4-AM $(5 \mu \mathrm{M})$ and $0.001 \%$ Pluronic F-127 (Molecular Probes, Eugene, OR, U.S.A.) and incubated in a $N$-(2-hydroxyethyl)piperazine- $N^{\prime}$-2-ethanesulfonic acid (HEPES)-buffered solution (150 mM NaCl, $5 \mathrm{~mm} \mathrm{KCl,} 1 \mathrm{~mm}$ $\mathrm{MgCl}_{2}, 10 \mathrm{~mm}$ HEPES, $10 \mathrm{~mm}$ glucose, $2 \mathrm{~mm} \mathrm{CaCl}_{2}$ ) for $1 \mathrm{~h}$ at $37^{\circ} \mathrm{C}$. Then, the cells were washed three times with a HEPES-buffered solution and maintained with a volume of $80 \mu \mathrm{l} /$ well in 96-well plates. For antagonist experiments, cells were pre-incubated with compounds for $15 \mathrm{~min}$ before the addition of an agonist. The fluorescence intensity $(F)$, and the initial fluorescence intensity $\left(F_{0}\right)$ were measured at $480 \mathrm{~nm}$. All data were collected and analyzed using the FDSS6000 system and related software (Hamamatsu Photonics, Japan).

Immunoblotting HEK293 cells stably expressing the 5$\mathrm{HT}_{6} \mathrm{R}$ were placed in 6 -well plates at a density of $1 \times 10^{5}$ cells/well. After $12 \mathrm{~h}$, the cells were incubated with serumfree DMEM for $2 \mathrm{~h}$, and each material was treated for the time duration indicated. Then, the cells were washed with cold phosphate buffered saline (PBS) and lysed with $1 \times$ sodium dodecyl sulfate (SDS) sample buffer [60 mm Tris$\mathrm{HCl}, 25 \%$ (v/v) glycerol, 2\% SDS, 1\% (v/v) 2-mercaptoethanol, $10 \mathrm{~mm} \mathrm{NaF}, 1 \mathrm{~mm} \mathrm{Na} \mathrm{VO}_{4}, 1 \mathrm{~mm}$ phenylmethylsulfonyl fluoride (PMSF), 0.1\% (w/v) bromophenol blue, $\mathrm{pH}$ 6.8]. After 10\% SDS-polyacrylamide gel electrophoresis (PAGE), the resulting proteins were transferred to polyvinylidene difluoride (PVDF) membranes that were blocked with Tris-buffered saline containing 5\% skim milk and $0.1 \%$ Tween-20 for $1 \mathrm{~h}$ at room temperature. After blocking, the membranes were incubated with primary antibodies $(1: 2000)$ in Tris buffered saline (TBS) containing 5\% skim milk and $0.1 \%$ Tween-20 overnight at $4{ }^{\circ} \mathrm{C}$. The membranes were then washed three times and incubated with diluted horse-radish peroxidase (HRP)-conjugated secondary antibodies $(1: 10000)$ in the TBS for $1 \mathrm{~h}$ at room temperature. After being washed three times, the membranes were visualized using an ECL kit (Milipore, U.S.A.).

Statistical Analysis Best-fit lines were used to analyze all concentration-response curves and were developed using Prism (GraphPad Software Inc., CA, U.S.A.) with the logistic equation

$$
y / y_{\max }=1 /\left(1+\left(k_{1 / 2} /[A]\right)^{n_{\mathrm{H}}}\right)
$$

where $y_{\max }$ is the maximum response, $k_{1 / 2}$ is the concentration for a half-maximum response $\left(\mathrm{EC}_{50}\right.$ or $\left.\mathrm{IC}_{50}\right),[A]$ is the total concentration of drugs, and $n_{\mathrm{H}}$ is the Hill coefficient. The data obtained were analyzed by ANOVA followed by Dunnett's test. A $p$ value of $<0.05$ considered statistically significant. All numeric numbers are represented as the mean \pm S.E.

\section{RESULTS}

Assay of Isolates of $C$. sinica as a 5-HT 6 R Antagonist Using the FDSS6000 We used the FDSS6000 system for $5-\mathrm{HT}_{6} \mathrm{R}$ and screened natural products to find novel ligands of the $5-\mathrm{HT}_{6} \mathrm{R}$. Examples of natural products screened are extracts of $C$. sinica, Glycyrrhiza uralensis, MULLBERRY (Morus spp.), Opuntia ficus-indica var. saboten MAKINO, Parthenocissus tricuspidata. Among them, we found that the ethyl acetate fraction from the root of $C$. sinica (537-18BE) showed the strongest inhibitory effect on $5-\mathrm{HT}_{6} \mathrm{R}$ activity. At a concentration of $10 \mathrm{mg} / \mathrm{ml}, 537-18 \mathrm{BE}$ produced $90.4 \pm$ $0.5 \%$ inhibition on 5 -HT-mediated $\mathrm{Ca}^{2+}$ increases in $5-\mathrm{HT}_{6} \mathrm{R}$ stably expressed HeLa cells. The $\mathrm{IC}_{50}$ values was $3.9 \pm$ $0.4 \mu \mathrm{g} / \mathrm{ml}$. Extracts of Glycyrrhiza uralensis, Mullberry (Morus spp.), Opuntia ficus-indica var. saboten MAKINO, and

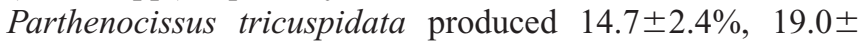
$2.0 \%, 18.8 \pm 3.9 \%$, and $37.0 \pm 3.7 \%$ inhibition, respectively. Therefore, we further isolated fractions of 537-18BE using various chromatographic separation steps such as silica gel, reverse phase, Sephadex LH-20 and Toyopearl HW-40C, and tested them on $5-\mathrm{HT}_{6} \mathrm{R}$ activity. We found three stilbene derivatives, $(+)-\alpha$-viniferin, miyabenol $\mathrm{C}$ and pallidol, produced more than $25 \%$ inhibition on $5-\mathrm{HT}_{6} \mathrm{R}$ activity. Among them, $(+)-\alpha$-viniferin showed the most potent antagonistic effect $\left(\mathrm{IC}_{50}=2.3 \pm 0.5 \mu \mathrm{M}\right.$, Fig. 1$)$ and miyabenol $\mathrm{C}$ also had a considerable inhibitory effect $\left(\mathrm{IC}_{50}=6.4 \pm 0.2 \mu \mathrm{M}\right)$. However, pallidol showed the weakest inhibitory effect among them with an $\mathrm{IC}_{50}$ value of $16.6 \pm 2.6 \mu \mathrm{M}$. The yield of $(+)-\alpha-$ viniferin, miyabenol $\mathrm{C}$ and pallidol was $0.054 \%, 0.008 \%$, and $0.002 \%$, respectively. We also examined SB258585, the selective antagonist of the $5-\mathrm{HT}_{6} \mathrm{R}$ and found that the $\mathrm{IC}_{50}$ value for SB258585 was $37.2 \pm 6.4 \mathrm{~nm}$. These results indicated that $(+)-\alpha$-viniferin, miyabenol $\mathrm{C}$ and pallidol could be important components for antagonistic effects of 537$18 \mathrm{BE}$ on human $5-\mathrm{HT}_{6} \mathrm{R}$ activity.

Effects of Isolates from $C$. sinica on Various Neurotransmitter Receptors Our FDSS6000-based 5- $\mathrm{HT}_{6} \mathrm{R}$ assay system provides a selective and direct measurement on $5-\mathrm{HT}_{6} \mathrm{R}$ activity because it used $5-\mathrm{HT}_{6} \mathrm{R}$ stably expressed 
A

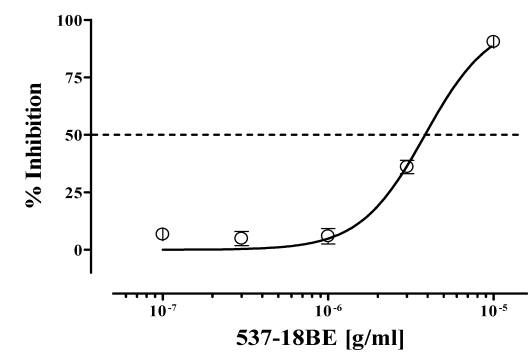

C

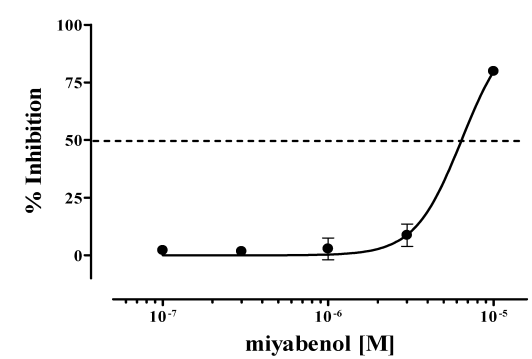

B

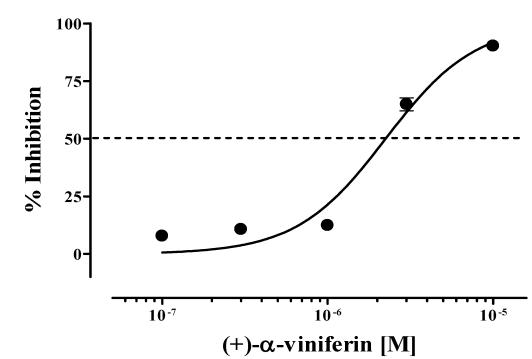

D

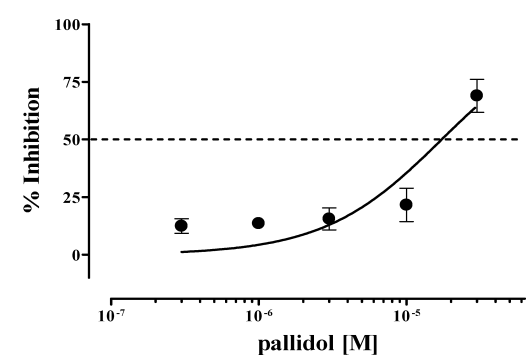

Fig. 1. Dose-Dependent Responses of 537-18BE, (+)- $\alpha$-Viniferin, Miyabenol C, and Pallidol

HeLa cells stably expressing the $5-\mathrm{HT}_{6} \mathrm{R}$ were transfected with $\mathrm{G} \alpha_{15}$ and loaded with Fluo-4-AM. Cells were then pre-incubated with one of the compounds for 15 min and treated with $100 \mathrm{~nm} 5$-HT. The percentage inhibition was calculated as $100 \times\left[\left(\mathrm{IV}_{5-\mathrm{HT}}-\mathrm{IV}_{\text {compound }}\right) / \mathrm{IV}_{5-\mathrm{HT}}\right]$ where IV represents the relative integrated values of fluorescent ratio $\left(F / F_{0}\right)$.

Table 1. Effects of 537-18BE and Three Stilbene Derivatives on 5- $\mathrm{HT}_{6}$ and Various Neurotransmitter Receptors

\begin{tabular}{lccccc}
\hline \hline & $\begin{array}{c}5-\mathrm{HT}_{6} \mathrm{R} \\
\text { \% Inhibition }\end{array}$ & $\begin{array}{c}5-\mathrm{HT}_{4} \mathrm{R} \\
\text { \% Inhibition }\end{array}$ & $\begin{array}{c}5-\mathrm{HT}_{7} \mathrm{R} \\
\text { \% Inhibition }\end{array}$ & $\begin{array}{c}\mathrm{M}_{1} \mathrm{R} \\
\text { \% Inhibition }\end{array}$ & $\begin{array}{c}\mathrm{D}_{2} \mathrm{R} \\
\text { \% Inhibition }\end{array}$ \\
\hline $537-18 \mathrm{BE}$ & $90.4 \pm 0.5$ & $9.2 \pm 4.1$ & $-0.2 \pm 3.4$ & $-8.5 \pm 7.6$ & $3.7 \pm 4.3$ \\
$(+)-\alpha$-Viniferin & $90.3 \pm 0.5$ & $8.7 \pm 5.5$ & $1.3 \pm 1.3$ & $-1.9 \pm 14.5$ & $58.7 \pm 1.9$ \\
Miyabenol C & $79.8 \pm 1.2$ & $5.1 \pm 6.0$ & $-6.1 \pm 9.3$ & $-3.0 \pm 3.9$ & $27.2 \pm 8.6$ \\
Pallidol & $25.2 \pm 6.2$ & $3.9 \pm 4.2$ & $18.8 \pm 2.2$ & $-4.2 \pm 6.3$ & $0.7 \pm 2.6$ \\
\hline
\end{tabular}

(+)- $\alpha$-Viniferin, miyabenol C and pallidol were tested at $10 \mu \mathrm{M}$, and $537-18 \mathrm{BE}$ was used at $10 \mu \mathrm{g} / \mathrm{ml}$. Data are represented as the mean \pm S.E. of three independent experiments. $\mathrm{M}_{1} \mathrm{R}$, muscarinic acetylcholine receptor $\mathrm{M} 1 ; \mathrm{D}_{2} \mathrm{R}$, dopamine receptor $\mathrm{D} 2$.

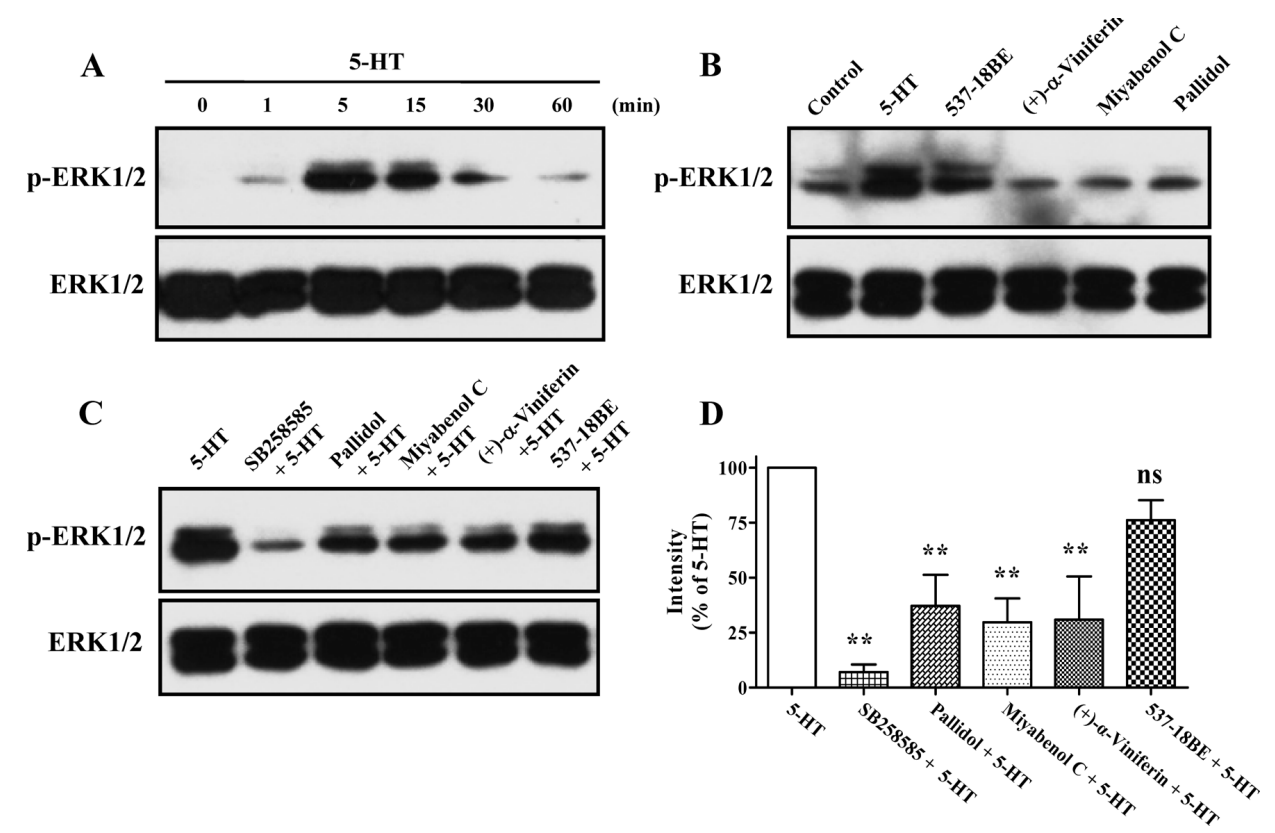

Fig. 2. Effects of (+)- $\alpha$-Viniferin, Miyabenol C, and Pallidol on ERK1/2 Phosphorylation

HEK293 cells stably expressing the $5-\mathrm{HT}_{6} \mathrm{R}$ were treated with one of the compounds for the time duration indicated (A) or 15 min (B). For the evaluation of antagonistic effects in (C), $100 \mathrm{~nm} 5$-HT was added and incubated for $5 \mathrm{~min}$ after the pretreatment with each compound for $15 \mathrm{~min}$. The total levels of ERK1/2 were detected as the loading control. (D) Quantitative analysis of relative ERK1/2 phosphorylation. (+)- $\alpha$-Viniferin, miyabenol C and pallidol were tested at $10 \mu \mathrm{M}$, and $537-18 \mathrm{BE}$ was used at $10 \mu \mathrm{g} / \mathrm{ml}$. $* * p<0.01$. 
mammalian cell lines such as Hela or HEK293. Therefore, we next investigated whether the compounds isolated from $C$. sinica affect other neurotransmitter receptors. We chose the 5-HT receptor $4\left(5-\mathrm{HT}_{4} \mathrm{R}\right)$ and $5-\mathrm{HT}$ receptor $7 \mathrm{~A}(5-$ $\mathrm{HT}_{7 \mathrm{~A}} \mathrm{R}$ ) because they are the same $\mathrm{G} \alpha_{\mathrm{S}}$ family receptors as the $5-\mathrm{HT}_{6} \mathrm{R}$. Muscarinic acetylcholine receptor M1 $\left(\mathrm{M}_{1} \mathrm{R}\right)$ and dopamine receptor $\mathrm{D} 2\left(\mathrm{D}_{2} \mathrm{R}\right)$ were also chosen as representative neurotransmitter receptors. Instead of using $5-\mathrm{HT}_{6} \mathrm{R}$ stably expressed cell lines, each receptor gene tested was transiently expressed in HEK293 cells and the receptor activity assayed using the FDSS6000 system. The results are summarized and compared with the effects on the $5-\mathrm{HT}_{6} \mathrm{R}$ in Table 1. Although $(+)-\alpha$-viniferin and miyabenol $\mathrm{C}$ showed modest antagonistic effect on $\mathrm{D}_{2} \mathrm{R}, 537-18 \mathrm{BE}$ and all three stilbene derivatives produced no or less than $20 \%$ inhibition on $5-\mathrm{HT}_{4}, 5-\mathrm{HT}_{7}$, or $\mathrm{M}_{1}$ receptors.

The Isolates from $C$. sinica Modulate 5-HT-Mediated ERK1/2 Phosphorylation The $5-\mathrm{HT}_{6} \mathrm{R}$ is a $\mathrm{G} \alpha_{\mathrm{S}}$-coupled receptor that couples with adenylate cyclase and consequently triggers a cAMP-dependent signaling pathway. A key signal transduction mediator in this pathway is the extracellular signal-regulated kinase $1 / 2$ (ERK1/2). We previously showed that 5-HT stimulates ERK1/2 phosphorylation in HEK293 cells stably expressing the $5-\mathrm{HT}_{6} \mathrm{R}^{10)}$ In the present study, the treatment with 5-HT similarly increased ERK1/2 phosphorylation. The 5-HT-mediated ERK1/2 phosphorylation was highest at $5 \mathrm{~min}$, and then gradually reduced with time (Fig. 2A). We then examined whether 537-18BE and three stilbene derivatives by themselves produce any effect on ERK1/2 phosphorylation. While 537-18BE increased ERK1/2 phosphorylation, $(+)-\alpha$-viniferin, miyabenol $\mathrm{C}$, and pallidol did not affect ERK1/2 phosphorylation (Fig. 2B). Since $537-18 \mathrm{BE}$ is a crude fraction, unidentified components could have been responsible for the effect of 537-18BE on ERK1/2 phosphorylation. We subsequently assessed whether (+)- $\alpha$-viniferin, miyabenol $\mathrm{C}$, and pallidol antagonize 5-HTmediated ERK1/2 phosphorylation as we observed using FDSS6000 system. As a standard, we used the selective 5$\mathrm{HT}_{6} \mathrm{R}$ antagonist, SB258585 $(10 \mu \mathrm{M})$. As shown in Figs. $2 \mathrm{C}, \mathrm{D},(+)-\alpha$-viniferin, miyabenol $\mathrm{C}$ and pallidol significantly inhibited 5-HT-mediated ERK1/2 phosphorylation. Unlike these single compounds, 537-18BE did not notably inhibit ERK1/2 phosphorylation. This may be due to the presence of unidentified compounds in 537-18BE that stimulate ERK1/2 (see Fig. 2B) and thereby mask the stilbene derivatives-mediated down-regulation of ERK1/2 phosphorylation.

\section{DISCUSSION}

Natural compounds, particularly those with a long history of traditional use, can be considered as safer than synthetic compounds and thus advantageous in terms of drug development. Many oriental plants used in Asian medicine have recently been proven to have pharmacological activity. For example, Ginseng has traditionally been used to treat disease in Korea and Kim et al. ${ }^{16,17)}$ have demonstrated that saponin, one of the active constituents of Ginseng, produces neuroprotective effects by inhibiting $N$-methyl-D-aspartic acid (NMDA) receptors or L-type $\mathrm{Ca}^{2+}$ channels. To find selective $5-\mathrm{HT}_{6} \mathrm{R}$ ligands from natural products, a reliable cell- based HTS assay for the $5-\mathrm{HT}_{6} \mathrm{R}$ was introduced. We found that $C$. sinica produced the most potent antagonistic activity against the $5-\mathrm{HT}_{6} \mathrm{R}$ among the natural products we tested. Furthermore, we demonstrated that (+)- $\alpha$-viniferin, miyabenol $\mathrm{C}$ and pallidol are active components for antagonistic effects of $C$. sinica on human $5-\mathrm{HT}_{6} \mathrm{R}$ activity. Although the inhibitory activities of (+)- $\alpha$-viniferin, miyabenol $\mathrm{C}$ and pallidol are lower than that of SB258585, commercially available $5-\mathrm{HT}_{6} \mathrm{R}$ antagonist, these are remarkable results given the concentration used, because, in general, natural compounds produce effects at somewhat higher doses than synthetic compounds. Our findings are valuable because we demonstrated the inhibitory activities of three stilbene derivatives on both the $5-\mathrm{HT}_{6}$ receptor level and a $5-\mathrm{HT}_{6} \mathrm{R}-$ dependent downstream signal pathway, ERK1/2.

Among the three stilbene derivatives we examined in the present study, $(+)-\alpha$-viniferin and miyabenol $\mathrm{C}$ are particularly interesting components. As anti-inflammatory activity, $(+)$ - $\alpha$-viniferin exhibited anti-inflammatory effects on in vivo model and dose-dependently inhibited the cyclooxygenase activity. ${ }^{13,18)}(+)-\alpha$-Viniferin- or miyabenol-mediated effects on protein kinase $\mathrm{C}$ (PKC), as a signal target of cancers and inflammatory disorders, were also reported. ${ }^{19)}(+)$ $\alpha$-Viniferin and miyabenol were shown to have an inhibitory effect on the in vitro activity of $\mathrm{PKC}$, partially purified from rat brain, with $\mathrm{IC}_{50}$ values of 62.5 and $52.0 \mu \mathrm{M}$, respectively. Based on our results, $(+)-\alpha$-viniferin and miyabenol $\mathrm{C}$ are also proven to be active components for antagonistic effects of $C$. sinica on $5-\mathrm{HT}_{6} \mathrm{R}$ activity with $\mathrm{IC}_{50}$ values of 2.3 and $6.4 \mu \mathrm{M}$, respectively. The $5-\mathrm{HT}_{6} \mathrm{R}$ is known to be involved in neurological disorders such as Alzheimer's diseases, depression, and cognition disorders. Therefore, since we only evaluated their antagonist effects in non-neuronal cells such as Hela or HEK293 cells, it is necessary to prove effects of (+)$\alpha$-viniferin and miyabenol in the CNS. As a CNS-related activity, Sung et al. ${ }^{20)}$ interestingly reported that (+)- $\alpha$ viniferin produced anti-acetylcholinesterase (AChE) activity in vitro with an $\mathrm{IC}_{50}$ value of $2.0 \mu \mathrm{M}$. The inhibitory effect of $(+)$ - $\alpha$-viniferin on $\mathrm{AChE}$ was specific, reversible and noncompetitive. These findings along with the effects on brain types of $\mathrm{PKC}^{19}$ ) are strongly providing the possible usage of these stilbene derivatives for the treatment of the CNS diseases.

In summary, the stilbene derivatives isolated from $C$. sinica can function as $5-\mathrm{HT}_{6} \mathrm{R}$ antagonists in basis of their effects on $5-\mathrm{HT}_{6} \mathrm{R}$-mediated $\mathrm{Ca}^{2+}$ responses and ERK1/2 phosphorylation. Further in vitro and in vivo studies in the CNS will be necessary to validate the usefulness of them as $5-\mathrm{HT}_{6} \mathrm{R}$ antagonists in the brain.

Acknowledgements This work was supported by a Midcareer Researcher Program Grant (No. 20100000343), the Brain Research Center of the 21st Century Frontier Research Program (No. 2010K000813 to H.R.), and the Pioneer Grant (No. 20100002215) from MEST, the Republic of Korea.

\section{REFERENCES}

1) Woolley M. L., Bentley J. C., Sleight A. J., Marsden C. A., Fone K. C., Neuropharmacology, 41, 210-219 (2001).

2) Mitchell E. S., Neumaier J. F., Pharmacol. Ther., 108, 320-333 (2005). 
3) Holenz J., Pauwels P. J., Diaz J. L., Merce R., Codony X., Buschmann H., Drug Discov. Today, 11, 283-299 (2006).

4) Monsma F. J. Jr., Shen Y., Ward R. P., Hamblin M. W., Sibley D. R., Mol. Pharmacol., 43, 320-327 (1993).

5) Plassat J. L., Amlaiky N., Hen R., Mol. Pharmacol., 44, 229-236 (1993).

6) Ruat M., Traiffort E., Arrang J. M., Tardivel-Lacombe J., Diaz J., Leurs R., Schwartz J. C., Biochem. Biophys. Res. Commun., 193, 268-276 (1993).

7) Kohen R., Metcalf M. A., Khan N., Druck T., Huebner K., Lachowicz J. E., Meltzer H. Y., Sibley D. R., Roth B. L., Hamblin M. W., J. Neurochem., 66, 47-56 (1996).

8) Svenningsson P., Tzavara E. T., Qi H., Carruthers R., Witkin J. M., Nomikos G. G., Greengard P., J. Neurosci., 27, 4201— 4209 (2007).

9) Kim H. J., Yun H. M., Kim T., Nam G., Roh E. J., Kostenis E., Choo H. Y., Pae A. N., Rhim H., Comb. Chem. High Throughput Screen., 11, 316-324 (2008).

10) Yun H. M., Kim S., Kim H. J., Kostenis E., Kim J. I., Seong J. Y., Baik J. H., Rhim H., J. Biol. Chem., 282, 5496-5505 (2007).

11) Yun H. M., Baik J. H., Kang I., Jin C., Rhim H., J. Biol. Chem., 285,
10016-10029 (2010).

12) Meng Q., Niu Y., Niu X., Roubin R. H., Hanrahan J. R., J. Ethnopharmacol., 124, 350-368 (2009).

13) Kitanaka S., Ikezawa T., Yasukawa K., Yamanouchi S., Takido M., Sung H. K., Kim I. H., Chem. Pharm. Bull., 38, 432- 435 (1990).

14) Ono M., Ito Y., Kinjo J., Yahara S., Nohara T., Niiho Y., Chem. Pharm. Bull., 43, 868-871 (1995).

15) Khan M. A., Nabi S. G., Prakash S., Zaman A., Phytochemistry, 25, 1945-1948 (1986).

16) Kim S., Kim T., Ahn K., Park W. K., Nah S. Y., Rhim H., Biochem. Biophys. Res. Commun., 323, 416 424 (2004).

17) Kim S., Nah S. Y., Rhim H., Biochem. Biophys. Res. Commun., 365, 399-405 (2008).

18) Lee S. H., Shin N. H., Kang S. H., Park J. S., Chung S. R., Min K. R., Kim Y., Planta Med., 64, 204-207 (1998).

19) Xu G., Zhang L. P., Chen L. F., Hu C. Q., Acta Pharmacol. Sin., 29, 818-822 (1994).

20) Sung S. H., Kang S. Y., Lee K. Y., Park M. J., Kim J. H., Park J. H., Kim Young-Chul, Kim J., Kim Young-Choong, Biol. Pharm. Bull., 25, 125-127 (2002). 